\title{
Spatially varying correlation between environmental conditions and human leptospirosis in Sarawak, Malaysia
}

\author{
Kira, R. ${ }^{1}$, Bilung, L.M. ${ }^{1 *}$, Ngui, R..$^{*}$, Apun, K. ${ }^{1}$, Su'ut, L. ${ }^{3}$ \\ ${ }^{1}$ Faculty of Resource Science and Technology, Universiti Malaysia Sarawak, 94300 Kota Samarahan, Sarawak, Malaysia \\ ${ }^{2}$ Department of Parasitology, Faculty of Medicine, University of Malaya, 50603 Kuala Lumpur, Malaysia \\ ${ }^{3}$ Faculty of Medicine and Health Science, Universiti Malaysia Sarawak, 94300 Kota Samarahan, Sarawak, Malaysia \\ *Corresponding author: mblesley@unimas.my; romano@um.edu.my
}

\section{ARTICLE HISTORY}

Received: 26 October 2020 Revised: 18 February 2021

Accepted: 22 February 2021

Published: 30 April 2021

\begin{abstract}
The spatial distribution of environmental conditions may influence the dynamics of vectorborne diseases like leptospirosis. This study aims to investigate the global and localised relationships between leptospirosis with selected environmental variables. The association between environmental variables and the spatial density of geocoded leptospirosis cases was determined using global Poisson regression (GPR) and geographically weighted Poisson regression (GWPR). A higher prevalence of leptospirosis was detected in areas with higher water vapour pressure $(\exp (\hat{a}): 1.12 ; 95 \% \mathrm{Cl}: 1.02-1.25)$ and annual precipitation $(\exp (\hat{a}): 1.15$; $95 \% \mathrm{Cl}: 1.02-1.31)$, with lower precipitation in the driest month $(\exp (\hat{a}): 0.85 ; 95 \% \mathrm{Cl}: 0.75-$ $0.96)$ and the wettest quarter $(\exp (\hat{a}): 0.88 ; 95 \% \mathrm{Cl}: 0.77-1.00)$. Water vapor pressure (WVP) varied the most in the hotspot regions with a standard deviation of 0.62 (LQ: $0.15 ; \cup Q ; 0.99$ ) while the least variation was observed in annual precipitation (ANNP) with a standard deviation of 0.14 (LQ: 0.11; UQ; 0.30). The reduction in AICc value from 519.73 to 443.49 indicates that the GWPR model is able to identify the spatially varying correlation between leptospirosis and selected environmental variables. The results of the localised relationships in this study could be used to formulate spatially targeted interventions. This would be particularly useful in localities with a strong environmental or socio-demographical determinants for the transmission of leptospirosis.
\end{abstract}

Keywords: Leptospira spp.; geostatistical analysis; map; risk factor; Borneo island.

\section{INTRODUCTION}

Leptospirosis is regarded as one of the most important emerging zoonotic diseases with worldwide distribution (Haake \& Levett, 2015). The causative organism is a spirochete bacterium in the genus Leptospira. Pathogenic Leptospira spp. is shed in the bodily fluids of reservoir hosts, and infection occurs when the pathogen penetrates abraded skins or mucosal membranes, or through transmission via contaminated water bodies or environment. The main vector of transmission are rodents, but a broad spectrum of domestic or wild animals can also be carriers of the pathogenic bacteria (Lau et al., 2010). Leptospirosis occurs worldwide but prominent occurrences are found in countries with tropical climates. In Malaysia, leptospirosis was gazetted as a notifiable disease since December 2010 under the Prevention and Control of Infectious Diseases Act 1988 (Ministry of Health Malaysia, 2011).

Climatic conditions are amongst the foremost factors for the endemicity and the persistence of leptospires in natural environment across different geographical and ecological regions (Victoriano et al., 2009; Lau et al., 2010;
Mwachui et al., 2015; Garba et al., 2018). Global climate change contributes toward the fluctuations in land and sea temperatures and increases in the frequency of tropical storms surges (Lau et al., 2010). Flooding is more frequent during the monsoon season as a result of the continuous rainfall, surface run-off, rising sea level, alteration of catchment size and topography. These complex interactions could lead to the emergence of new areas for optimal survival and transmission of leptospirosis. Leptospires has been reported to survive longer in river water in comparison to acidic sea water (Khairani-Bejo et al., 2004). Higher frequency of leptospirosis cases in Malaysia were recorded between $27^{\circ} \mathrm{C}$ to $28^{\circ} \mathrm{C}$ (Benacer et al., 2016). Previous studies also discussed leptospirosis outbreaks following the occurrence of extreme weather in tropical countries such as Philippines, Laos, India and Malaysia (Pappachan et al., 2004; Kawaguchi et al., 2008; Al-shere et al., 2012; Radi et al., 2018).

As an initiative to improve disease prevention and control measures, it is imperative to consider underlying environmental determinants, which may act as a modifiable predictor for diseases like leptospirosis. While these factors may be unevenly distributed, their spatial distribution may 
influence the dynamics of leptospirosis. According to Nakaya (2005), the ecological association of diseases may vary geographically as covariates change across different geographical contexts (Nakaya, 2005). Geographically Weighted Regression (GWR) analysis allows estimated regression associations by using weighted estimation where near observations are weighted more heavily than distant ones. This method has been used to study the association of spatial variations between health access, disease counts and risks, incidence rates, mortality risks and socioeconomic characteristics (Nakaya et al., 2005; Cheng et al., 2011; Comber et al., 2011; Weisent et al., 2012; Odoi \& Busingye, 2014).

In Sarawak, leptospirosis escalated from 49 cases in 2010 to 616 cases in 2014, with a total of 53 deaths during that period (Su'ut et al., 2016). The establishment of a public health surveillance system remains essential in achieving better control of this disease and should be in parallel with the rapid industrialisation of Sarawak. In this study, it is posited that there are significant relationships between the environmental variables with the spatial distribution of leptospirosis, and that the associations are dynamic across the study region. This study aims to evaluate the relationship between the leptospirosis cases with selected geospatial environmental variables and explores the potential of a spatially heterogeneous association using a local model. This study applied spatial statistical modelling as a tool for analysing disease maps arising from the spatially dynamic processes. This is the first study in Sarawak to incorporate spatial analysis in understanding the epidemiology of leptospirosis.

\section{MATERIALS AND METHODS}

\section{Study Area}

The study area is located in the southeast region of Sarawak, Malaysia (Figure 1) and included five districts; Kapit, Song, Belaga, Lubok Antu, and Tatau. Since the first report of leptospirosis in 2010, there has been a significantly higher number of leptospirosis cases in this region (Thayaparan et al., 2015; Su'ut et al., 2016). Vector data for the study area was retrieved from the Database of Global Administrative Areas, GADM, on $7^{\text {th }}$ September 2018 (Hijmans, 2018).

\section{Human Leptospirosis Cases}

Ethical approval for the study was obtained from the National Medical Research (NMRR, Ethical Number: 18-2713-42365), Ministry of Health Malaysia (MOH) and Sarawak State Planning Unit, SPU. Reported leptospirosis cases in Sarawak from the years 2011 to 2018 were retrieved from the Infectious Disease Unit, Sarawak State Health Department. All data obtained were anonymous to ensure confidentiality. Cases were confirmed through clinical evaluation and laboratory diagnostic tests.

\section{Geospatial Environmental Data}

A total of eight geospatial climatic variables which were retrieved from CHELSA (Karger et al., 2016) and WorldClim (Fick \& Hijmans, 2017) were included in this study. The list of variables in this study is presented in Table 1 and Figure 2. Spatial data processing and management were conducted in ArcGIS 10.3 software (Environmental System Research Institute, 2011).

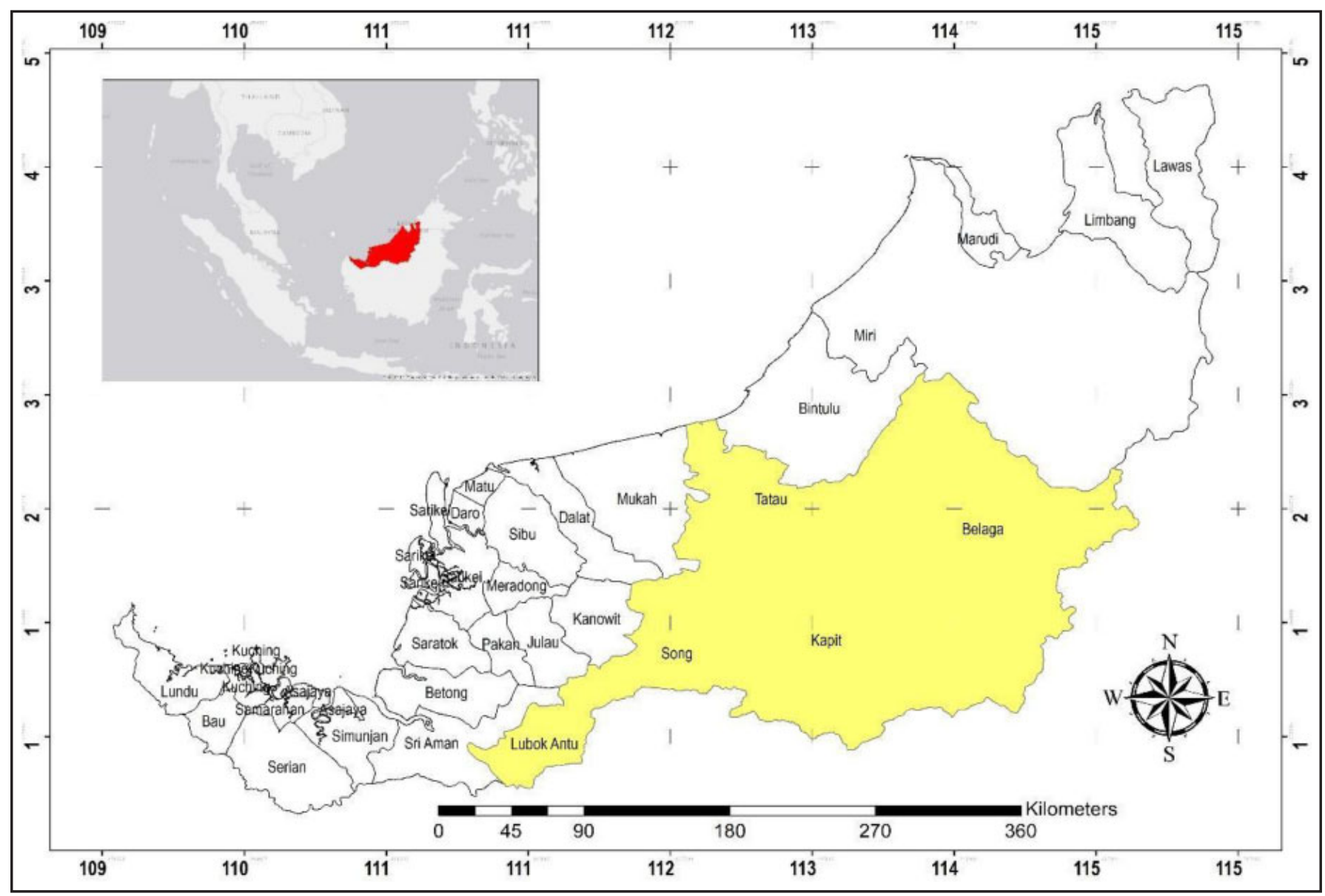

Figure 1. Location of the study area is shaded in yellow. The smaller map on the top left shows the location of Sarawak state in Southeast Asia. District boundary was retrieved from the Database of Global Administrative Areas (Hijmans, 2018). 
Table 1. List of geospatial environmental data collected for this study

\begin{tabular}{lll}
\hline Variables (unit) & Types & Resolution \\
\hline Water Vapour pressure, WVP (kPa) & Raster & 30 arcsec, $\sim 1 \mathrm{~km}$ \\
Annual Precipitation, ANNP (mm/year) & Raster & 30 arcsec, $\sim 1 \mathrm{~km} \quad$ Worldclim (Fick \& Hijman, 2017) \\
Precipitation in Driest Month, PDM (mm/month) & Raster & 30 arcsec, $\sim 1 \mathrm{~km} \quad$ CHELSA (Karger et al., 2016) \\
Precipitation in Wettest Quarter, PWQ (mm/quarter) & Raster & 30 arcsec, $\sim 1 \mathrm{~km} \quad$ CHELSA (Karger et al., 2016) \\
\hline
\end{tabular}

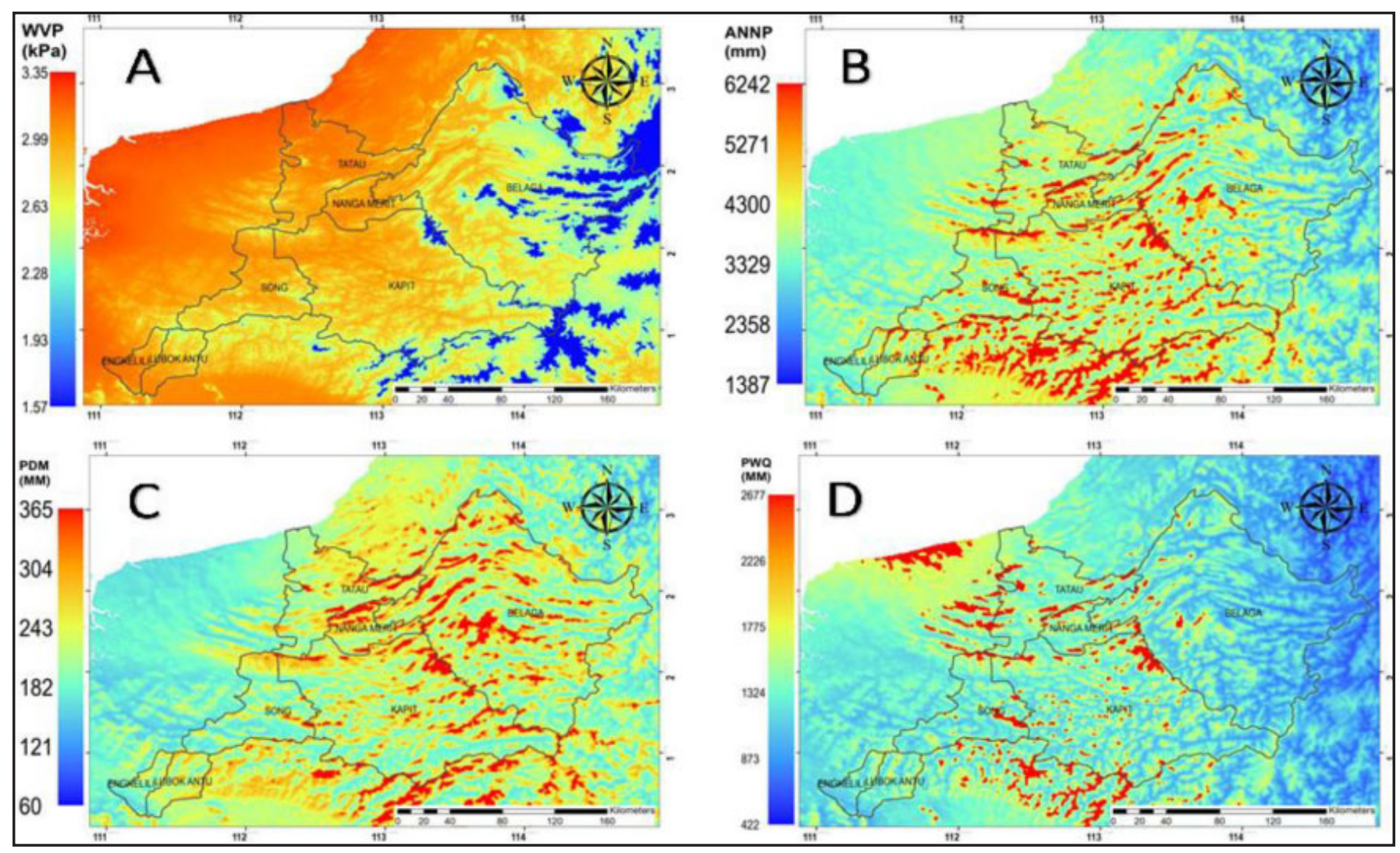

Figure 2. Geospatial environmental variables of the study region; A: water vapour pressure; B: annual precipitation; C: precipitation in the driest month; D: precipitation in the wettest quarter. District boundary was retrieved from the Database of Global Administrative Areas (Hijmans, 2018). Geospatial environmental data was retrieved from CHELSA (Karger et al., 2016) and WorldClim (Fick \& Hijmans, 2017).

\section{Response and Explanatory Variables}

Individual leptospirosis cases in the study region were geocoded using latitude and longitude of residential addresses which were derived using Google Earth Pro (version 7.3.2) as shown in Figure 3. The effect of the geographical inaccuracy of geocoded data was reduced by aggregating spatial points into $1 \times 1 \mathrm{~km}$ square grid (Rood et al., 2017). A grid size of $1 \mathrm{~km}$ was chosen as the analytical unit because it contained more details of geospatial environmental data. The number of events within each square was used as an attribute value representing the case count and was used as the response variable in the regression analysis. Sampling blocks were intersected with environmental data layers to extract data within each cell grid. All variables are standardized to have a mean of zero and a standard deviation of 1 , enabling a direct comparison of the parameter estimates (Vega-Corredor \& Opadeyi, 2014).
Global Poisson Regression (GPR) and Geographically Weighted Poisson Regression (GWPR)

The relationship between environmental risk factors was first evaluated using global Poisson regression (GPR). The Poisson model was adopted following the leptospirosis data characteristics, which were expected to follow Poisson distribution due to the low number of counts observed (Lovett \& Flowerdew 1989). Variance inflation factors (VIF) were estimated to enable the examination of relations among all the independent variables and check for multicollinearity. In this study, any VIF value greater than 4 (VIF $>4$ ) was eliminated and the assessment of model fit was performed using the goodness-of-fit test.

The spatially heterogeneous effect of the selected variables was assessed using geographically weighted Poisson regression by allowing the estimated regression associations to vary smoothly across a study area. In this 


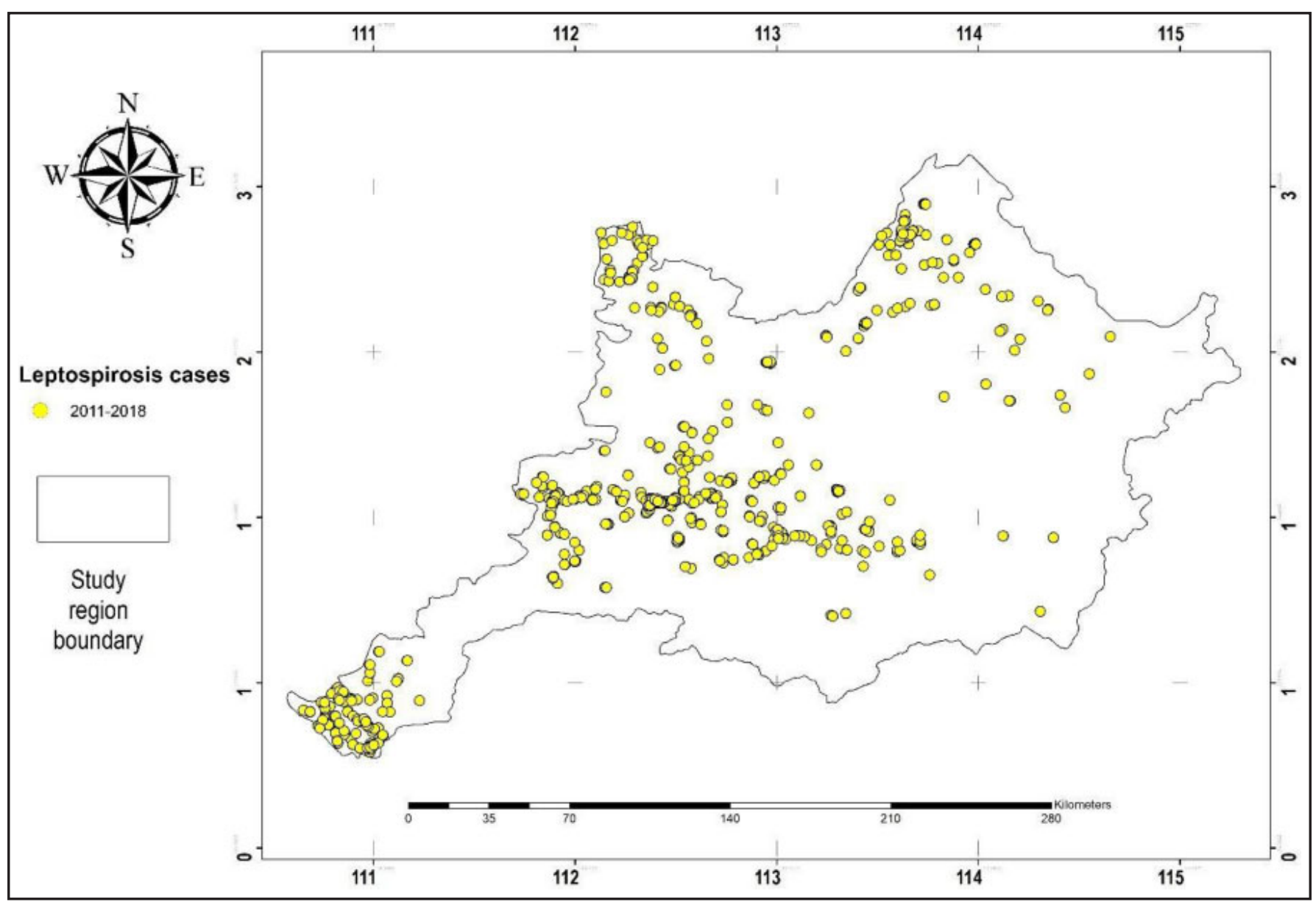

Figure 3. The geocoded leptospirosis cases from 2011 to 2018 in the study region, located in the south-east of Sarawak. District boundary was retrieved from the Database of Global Administrative Areas (Hijmans, 2018).

study, the calibration of the best kernel and bandwidth type was performed by comparing four kernel types in GWPR; fixed Gaussian, fixed bi-square, adaptive Gaussian and adaptive bi-square. The Akaike Information Criterion corrected (AICC) with golden selection bandwidth were employed as GWPR indicators to complete the model calibration. Global Moran's I was employed to examine the spatial autocorrelations of residuals of the GWPR model to ensure that non-stationary effects were accounted for. The GWPR analysis was conducted using the software GWR version 4.0 (GWR4, 2014).

\section{Mapping odds ratios and $t$-values}

After GWPR model calibration, pseudo-t-statistic and standard odds ratio were mapped to assess the significance of the parameters (Vega-Corredor \& Opadeyi, 2014). All products in the geographic coordinate system were referenced to the World Geodetic System (WGS 84) horizontal datum, with the horizontal coordinates expressed in decimal degrees. Spatial data processing and management were conducted in ArcMap and geostatistical modelling was conducted using geostatistical analyst toon in ArcGIS 10.3 software.

\section{RESULTS}

\section{General characteristic of the cases}

A total of 916 cases were reported in the study region. The average reported incidents were 58 cases (per 100000 population) per year. Males accounted for $70 \%$ of the total cases with an average incidence of 92 cases (per 100 000) per year. Leptospirosis infection in the study area predominantly occurred among people aged between 40-49 years, with an average incidence of 93 cases (per 100 000) per year. The lowest incidence rate was observed in the group aged between $0-9$, with an average of 10 cases per year. Most of the cases involved people in elementary occupations, making up $42 \%$ of the overall cases. According to the Malaysia Standard Classification of Occupations (MASCO), elementary occupation is described as performing simple, routine and non-systematic tasks which mainly require the use of handheld tools or simple machines, and in some cases, considerable physical effort (Ministry of Human Resource Malaysia, 2013). This includes cleaners and helpers, those in agricultural, forestry, farming, and fishery labourers, food preparation assistants, and sales and service workers.

\section{Global Poisson Regression (GPR)}

Leptospirosis cases in the study region were significantly associated with higher water vapour pressure $(\beta=0.12)$, higher annual precipitation $(\beta=0.14)$, lower precipitation in the driest month $(\beta=-0.16)$ and lower precipitation in the wettest quarter $(\beta=-0.12)$ (Table 2). From Table 2, all parameter estimates displayed statistical significance $(|z|>1.96$ at the $95 \%$ confidence level) in the global model. The global Poisson model demonstrated a residual deviance of 509.61 at $d f=490$, which was substantially lower than the null deviance with 539.58 at $d f=494$. Goodness-of-fit for the final model was tested using deviance chi-squared test and was found to be not significant $(p=0.26)$, an indication that the 
Table 2. Summary of parameter estimates for GPR analysis

\begin{tabular}{lccccc}
\hline Variables & $\beta$ & $\begin{array}{c}\text { Std. } \\
\text { error }\end{array}$ & $\operatorname{Exp}(\beta)(95 \% \mathrm{Cl})$ & $\operatorname{Pr}(>|\mathrm{z}|)$ & VIF \\
\hline intercept & 0.54 & 0.03 & $1.72(1.61-1.84)$ & $<0.01^{*}$ & \\
WVP (kPa) & 0.12 & 0.05 & $1.12(1.02-1.25)$ & $0.02^{*}$ & 1.95 \\
ANNP (mm) & 0.14 & 0.06 & $1.15(1.02-1.31)$ & $0.02^{*}$ & 3.05 \\
PDM (mm) & -0.16 & 0.06 & $0.85(0.75-0.96)$ & $0.01^{*}$ & 3.36 \\
PWQ (mm) & -0.12 & 0.07 & $0.88(0.77-1.00)$ & $0.05^{*}$ & 2.84 \\
\hline
\end{tabular}

*significant at $p<0.05 ; \beta$ : variable coefficients; Exp: exponential function; WVP: water vapour pressure; ANNP: annual precipitation; PDM: Precipitation in Driest Month; PWQ: Precipitation in the wettest quarter.

model fit the data well. The global Poisson regression results are summarised in Table 2.

\section{Geographically Weighted Poisson Regression (GWPR)}

As indicated by the reduced AICC value, there was a significant improvement in the model fitting using GWPR in comparison to the global model. The AICC value decreased from 519.73 in the global model (GPR) to 506.32 (fixed Gaussian), 484.05 (fixed Bi-square), 443.49 (adaptive Gaussian) and 456.03 (adaptive $\mathrm{Bi}$-square). The model with adaptive kernel and Gaussian bandwidth function showed the lowest AICc with a bandwidth size of $43 \mathrm{~km}$, indicating a better fit to the observed data. The percentage of deviance also revealed a substantial difference from 0.05 in the global model, to 0.32 in the local model. These values indicate that the GWPR model better explained the relationship between environmental factors and leptospirosis by allowing these relationships to vary spatially. As spatial heterogeneity was captured in the GWPR model, the model residuals (observed - predicted) did not demonstrate spatial autocorrelations (global Moran's $I=-0.003, p=0.48$ ). The comparison of the global model with the local model is summarised in Table 3.

\section{Mapping Odds ratio and $t$-values}

The descriptive statistics for the odds ratio and pseudo-tvalues of each variable is summarised in Table 4. Among the variables fitted to the GWPR model, water vapour pressure (WVP) had the most variation in effect with a standard deviation of 0.62 (LQ: 0.15; UQ; 0.99). The negative value of -4.14 in the difference of criterion for WVP confirmed that the variable had spatial variability. In contrast, the least variation was observed in annual precipitation (ANNP) with a standard deviation of 0.14 (LQ: 0.11; UQ; 0.30). In Figure 4, water vapour pressure had the most variation in the odds ratio as indicated by the higher values in the central region $(O R>1)$ and the lower values in the northern and northeast region $(O R<1)$. Among the variables fitted to the GWPR model, annual precipitation (ANNP) had the least variation in spatial effect. This was proven by the low odds ratio between -0.15 to $0.60(\mathrm{OR}<1)$ with the lowest standard deviation (SD: 0.14$)$ in comparison to the other covariates.

\section{DISCUSSION}

The geographically inconsistent patterns of leptospirosis observed in this study could be explained by the localised influence of environmental factors. The variable WVP was found to exhibit spatial variability (-4.14 difference of criterion), thereby suggesting that its influence towards leptospirosis was more localised. The positive relationship indicates that as water vapour pressure and annual rainfall increases, the spatial density of leptospirosis cases also increases. This finding supports existing paradigms in Sarawak where high annual rainfall in the Rejang Basin and seasonal flooding during the monsoon season have

Table 3. Comparison of global (GPR) and local (GWPR) models statistics

\begin{tabular}{|c|c|c|c|c|c|c|}
\hline \multirow{2}{*}{ Model } & \multicolumn{3}{|c|}{ Diagnostics } & \multirow{2}{*}{$\begin{array}{l}\text { Optimum } \\
\text { Bandwidth }(\mathrm{km})\end{array}$} & \multirow[b]{2}{*}{ Deviance } & \multirow{2}{*}{$\begin{array}{c}\text { Deviance } \\
\text { Explained (\%) }\end{array}$} \\
\hline & $\mathrm{AICc}$ & AIC & $\mathrm{BIC} / \mathrm{MDL}$ & & & \\
\hline Global & 519.73 & 519.61 & 640.63 & NA & 509.61 & 0.06 \\
\hline Fixed Gaussian* & 506.32 & 505.98 & 541.96 & 1.00 & 488.86 & 0.09 \\
\hline Fixed Bi-square* & 484.05 & 481.72 & 578.30 & 1.03 & 484.06 & 0.19 \\
\hline Adaptive Gaussian* & 443.49 & 437.48 & 591.23 & 43.00 & 364.35 & 0.32 \\
\hline Adaptive Bi-square* & 456.03 & 444.40 & 655.62 & 98.00 & 343.93 & 0.36 \\
\hline
\end{tabular}

*local model (GWPR).

AICC; corrected Akaike Information Criterion; AIC: Akaike Information Criterion; BIC: Bayesian Information Criterion, MDL: Minimum Description Lengt.

Table 4. Summary statistics of variable coefficients based on adaptive Gaussian kernel model

\begin{tabular}{|c|c|c|c|c|c|c|c|}
\hline \multirow{2}{*}{ Variable } & \multicolumn{3}{|c|}{ Odds Ratio } & \multicolumn{3}{|c|}{ Pseudo-t-values } & \multirow{2}{*}{ DIFF of Criterion } \\
\hline & Robust SD & LQ & UQ & Min & Max & SD & \\
\hline WVP & 0.62 & 0.15 & 0.99 & -1.25 & 5.85 & 1.64 & -4.14 \\
\hline PWQ & 0.28 & -0.23 & 0.15 & -2.28 & 3.44 & 1.44 & 3.57 \\
\hline PDM & 0.35 & -0.51 & -0.04 & -5.01 & 1.07 & 1.65 & 0.93 \\
\hline ANNP & 0.14 & 0.11 & 0.3 & -0.63 & 2.49 & 0.71 & 7.06 \\
\hline
\end{tabular}

WVP: water vapour pressure; PWQ: precipitation in the wettest quarter; PDM: precipitation in the driest month; ANNP: annual precipitation; SD; standard deviation; LQ: lower quartile; UQ; upper quartile; Min: minimum; Max; maximum. 


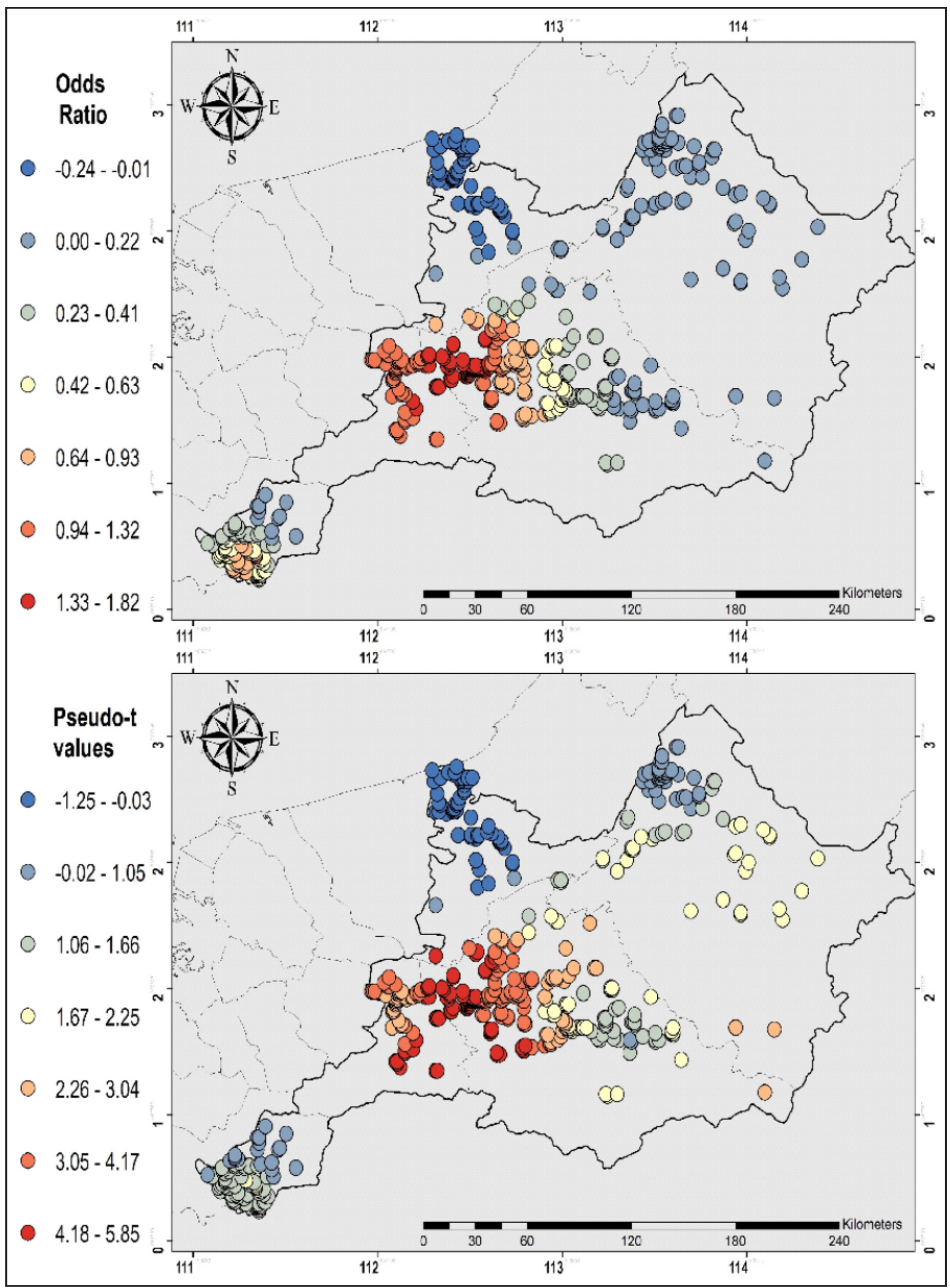

Figure 4. The geographical distribution of odds ratios and pseudo-t-values for water vapour pressure (WVP). District boundary was retrieved from the Database of Global Administrative Areas (Hijmans, 2018). 
contributed to the high seroprevalence in those areas (Su'ut et al., 2016). As the pressure increases, water vapour condenses into water droplets, thereby promoting precipitation and humidity. A study by Wang et al. (2016) demonstrated a positive correlation between precipitation and mean water vapour pressure. The increase in precipitation and mean water vapour pressure encourages the formation of small lakes, muddy ponds, and streams, which can prolong the survival of Leptospira in the natural environment. The high odds ratio in the central region suggests that as water vapour pressure increases, spatial density of leptospirosis increases. This pattern of sensitivity indicates that leptospirosis is more prevalent in the central region where water vapour pressure is higher.

An exception to this pattern was observed in the northern region of Tatau, where the odds ratio was much lower despite an increase in water vapour pressure. This area is closer to the coastal region, and environmental conditions like temperature, wind speed and humidity may fluctuate at a higher rate. These conditions could influence soil water retention capacity and water $\mathrm{pH}$, which in turn may affect the survival of leptospirosis in the natural environment. A study by Khairani-Bejo et al. reported that leptospires survive longer in soil with high moisture content in shaded environment (Khairani-Bejo et al., 2004).

Conventionally, the amount of precipitation has a positive relationship with leptospirosis (Victoriano et al., 2009; Chadsuthi et al., 2012; Benacer et al., 2016). However, the results of this study found that the spatial density of leptospirosis cases were concentrated in areas with lower precipitation in the driest month (PDM) and the wettest quarter (PWQ). Although this is counter-intuitive, the relationships were very weak, as indicated by the small pseudo-t-values, thereby suggesting that the relationships vary geographically. A decrease in precipitation may have influenced human activities and animal mobility during the wet and dry seasons. The dry period in Sarawak is associated with the southwest monsoon, which extends from May to September, while the wet season is between November to February (Dindang et al., 2013). A decrease in precipitation reduces water surface availability and may encourage waterbased activities for humans and animals like swimming, bathing and drinking (Lau et al., 2010). This would promote contact between humans, livestock and wildlife through sharing of the depleting surface water sources. For instance, in some remote areas of Sarawak, the access to clean water is limited and the local community relies on rivers and streams as their primary source of water. Such practices increase the risk of acquiring Leptospira spp. especially when the water bodies have been contaminated by the excreta of infected animals. In Indonesia, harvesting season was identifed as a critical period for the transmission of leptospirosis, due to the increase in human activities and frequent contact with contaminated water bodies (Widiastuti et al., 2019).

The GWPR model was able to identify the spatially varying correlation between leptospirosis and the selected environmental variables. This was supported by the reduction in the AICc value of the local model in comparison to its global counterpart. A similar observation was reported by Vega-Corredor \& Opadeyi (2014), where the GWPR model was able to demonstrate the spatially varying correlation between hydrological factors and leptospirosis on the island of Trinidad. In their study, a strong local relationship was observed when rainfall was excluded from the model as evidenced from the change in bandwidth size (Vega-Corredor \& Opadeyi, 2014).

By applying GWR, the spatial structure is accounted for and estimates a discrete model and local parameter for a unique geographical location using a weighted scheme (Matthews \& Yang, 2012). In this study, the model with an adaptive Gaussian kernel function exhibits a more localised effect as seen in the reduction of bandwidth size. As bandwidth increases, the GWPR model leans towards the GPR model due to the increased smoothing of weights in the data points. Estimates may also become biased due to the increasing distance of data from the regression point (Fotheringham et al., 2003; Vega-Corredor \& Opadeyi, 2014). Standard global modelling techniques, such as ordinary least square (OLS) linear regression cannot detect nonstationarity and may obscure regional variation in the relationships between predictors and response variables (Matthews \& Yang, 2012).

While the data presented in this study can be beneficial in identifying high-risk areas for more directed surveillance and interventions, some study limitations need to be considered. This study only incorporated confirmed leptospirosis cases in the analyses. However, there could be unreported cases of subclinical infection, and those who were undiagnosed, especially in the resource-limited rural areas of Sarawak. While this study highlighted the application of GWPR to study spatially varying relationships, it is important to consider that ecological studies such as this one are unable to identify causation. Hence, a multiparametric study is required to investigate the risk factors related to the ecology of Leptospira and the pathology of leptospirosis.

\section{CONCLUSION}

In conclusion, this study identified significant associations between leptospirosis and environmental variables, thereby supporting the first hypothesis of this study. This was demonstrated by the results of regression modelling where the geographical distribution of leptospirosis was concentrated in areas with higher water vapour pressure and annual precipitation, with lower precipitation in the driest month and the wettest quarter. Interestingly, the use of geographically weighted Poisson regression (GWPR) model revealed that the relationships were spatially heterogeneous. The spatially varying odds ratio and pseudo-t-values supported the second hypothesis of this study, where the relationships that exist between explanatory variables and the incidence of leptospirosis are spatially heterogenous across the high-risk regions.

\section{AKNOWLEDGEMENTS}

We would like to thank the Director-General of Health Malaysia for his permission to publish this article. This study was funded by Tun Zaidi Chair Grant (F07/T2C/1595/2017), Universiti Malaysia Sarawak.

\section{Conflict of Interests}

The funders had no role in study design, data collection and analysis, decision to publish, or preparation of the manuscript. All authors have no conflict of interest concerning the work reported in this paper. 


\section{REFERENCES}

Al-shere, T.A., Ujiie, M., Suzuki, M., Salva, E., Belo, M.C., Koizumi, N., Yoshimatsu, K., Schmidt, W.P., Marte, S. \& Dimaano, E.M. (2012). Outbreak of leptospirosis after flood, the Philippines, 2009. Emerging Infectious Diseases 18: 91-94. https://doi.org/10.3201/eid1801.101892

Bagirov, A.M., Mahmood, A. \& Barton, A. (2017). Prediction of monthly rainfall in Victoria, Australia: Clusterwise linear regression approach. Atmospheric Research 188: 20-29. https://doi.org/10.1016/j.atmosres.2017.01.003

Benacer, D., Thong, K.L., Min, N.C., Verasahib, K.B., Galloway, R.L., Hartskeerl, R.A., Souris, M. \& Zain, S.N. (2016). Epidemiology of human leptospirosis in Malaysia, 20042012. Acta Tropica 157: 162-168. https://doi.org/10.1016/ j.actatropica.2016.01.031

Chadsuthi, S., Modchang, C., Lenbury, Y., lamsirithaworn, S. \& Triampo, W. (2012). Modeling seasonal leptospirosis transmission and its association with rainfall and temperature in Thailand using time-series and ARIMAX analyses. Asian Pacific Journal of Tropical Medicine 5: 539546. https://doi.org/10.1016/s1995-7645(12)60095-9

Cheng, E.M., Atkinson, P.M. \& Shahani, A.K. (2011). Elucidating the spatially varying relation between cervical cancer and socio-economic conditions in England. International Journal of Health Geographics 10: 51-67. https://doi.org/10.1186/ 1476-072x-10-51

Comber, A.J., Brunsdon, C. \& Radburn, R. (2011). A spatial analysis of variations in health access: linking geography, socio-economic status and access perceptions. International Journal of Health Geographics 10: 44-54. https:// doi.org/10.1186/1476-072x-10-44

Dindang, A., Taat, A., Phuah, E.B., Alwi, A.M., Mandai, A.A., Adam, S.F., Othman, F.S., Bima, D.A. \& Lah, D. (2013). Statistical and trend analysis of rainfall data in Kuching, Sarawak from 1968-2010. Jabatan Meteorologi Malaysia Research Publication 6: 17-33.

Environmental Systems Research Institute (ESRI), (2014). ArcGIS Desktop 10.3 Version.

Fick, S.E. \& Hijmans, R.J. (2017). WorldClim 2: new 1 km spatial resolution climate surfaces for global land areas. International Journal of Climatology 37: 4302-4315. https://doi.org/ 10.1002/joc.5086

Fotheringham, A.S., Brunsdon, C. \& Charlton, M. (2003). Geographically weighted regression: the analysis of spatially varying relationships. Chichester: John Wiley \& Sons, pp 54-55.

Garba, B., Bahaman, A.R., Bejo, S.K., Zakaria, Z., Mutalib, A.R. \& Bande, F. (2018). Major epidemiological factors associated with leptospirosis in Malaysia. Acta Tropica 178: 242-247. https://doi.org/10.1016/j.actatropica.2017. 12.010

Haake, D.A. \& Levett, P.N. (2015). Leptospirosis in humans. In: Leptospira and leptospirosis. Berlin: Springer, pp. 65-97.

Hijmans, R.J. (2018). GADM database of Global administrative areas. Gadm.org. https://gadm.org/index.html. Accessed 7 September 2018.

Karger, D.N., Conrad, O., Böhner, J., Kawohl, T., Kreft, H., SoriaAuza, R.W., Zimmermann, N.E., Linder, H.P. \& Kessler, M. (2017). Climatologies at high resolution for the earth's land surface areas. Scientific Data 5: 170-172. https:// doi.org/10.1038/sdata.2017.122
Kawaguchi, L., Sengkeopraseuth, B., Tsuyuoka, R., Koizumi, N., Akashi, H., Vongphrachanh, P., Watanabe, H. \& Aoyama A. (2008). Seroprevalence of leptospirosis and risk factor analysis in flood-prone rural areas in Lao PDR. The American Journal of Tropical Medicine and Hygiene 78: 957961. https://doi.org/10.4269/ajtmh.2008.78.957

Khairani-Bejo, S., Oii, S.S. \& Bahaman, A.R. (2004). Rats: leptospirosis reservoir in Serdang Selangor residential area. Journal of Animal and Veterinary Advances 3: 66-69.

Lau, C.L., Smythe, L.D., Craig, S.B. \& Weinstein, P. (2010). Climate change, flooding, urbanisation and leptospirosis: fuelling the fire? Transactions of the Royal Society of Tropical Medicine and Hygiene 104: 631-638. https://doi.org/10.1016/ j.trstmh.2010.07.002

Lovett, A. \& Flowerdew, R. (1989). Analysis of count data using Poisson regression. The Professional Geographer 41: 190198.

Matthews, S.A. \& Yang, T.C. (2012). Mapping the results of local statistics: Using geographically weighted regression. Demographic Research 26: 151-166. https://dx.doi.org/ 10.4054/DemRes.2012.26.6

Matsushita, N., Ng, C.F.S., Kim, Y., Suzuki, M., Saito, N., Ariyoshi, K. \& Hashizume, M. (2018). The non-linear and lagged short-term relationship between rainfall and leptospirosis and the intermediate role of floods in the Philippines. PLoS Neglected Tropical Diseases 12: 1-13. https://doi.org/ 10.1371/journal.pntd.0006331

Ministry of Health Malaysia. (2011). Guidelines for the Diagnosis, Management, Prevention and Control of Leptospirosis in Malaysia. www.moh.goy.my. https://www. moh.gov.my/moh/resources/auto/20download/ 20images/589d71cb177d8.pdf. Accessed 9 September 2018.

Ministry of Human Resource Malaysia. (2013). Malaysian Standard Classification of Occupations (MASCO). www.mohr.goy.my. http://jtksm.mohr.gov.my/en/sumber sumber/penerbitan/garis-panduan/814-malaysiastandard-classification occupations masco-2013.pdf. Accessed 18 March 2019.

Mwachui, M.A., Crump, L., Hartskeerl, R., Zinsstag, J. \& Hattendorf, J. (2015). Environmental and behavioural determinants of leptospirosis transmission: a systematic review. PLoS Neglected Tropical Diseases 9: e0003843. https://doi.org/10.1371/journal.pntd.0003843

Nakaya, T., Fotheringham, A.S., Brunsdon, C. \& Charlton, M. (2005). Geographically weighted Poisson regression for disease association mapping. Statistics in Medicine 24: 2695-2717. https://doi.org/10.1002/sim.2129

Odoi, A. \& Busingye, D. (2014). Neighborhood geographic disparities in heart attack and stroke mortality: comparison of global and local modeling approaches. Spatial and Spatio-Temporal Epidemiology 1: 109-123. https://doi.org/10.1016/j.sste.2014.10.001

Pappachan, M.J., Mathew, S.H., Aravindan, K.P., Khader, A.Y., Bharghavan, P.V., Kare, M.M., Tuteja, U.R., Shukla, J.Y. \& Batra, H.V. (2004). Risk factors for mortality in patients with leptospirosis during an epidemic in northern Kerala. National Medical Journal of India 17: 240-242.

Radi, M.F., Hashim, J.H., Jaafar, M.H., Hod, R., Ahmad, N., Nawi, A.M., Baloch, G.M., Ismail, R. \& Ayub, N.I. (2018). Leptospirosis outbreak after the 2014 major flooding event in Kelantan, Malaysia: a spatial-temporal analysis. The American Journal of Tropical Medicine and Hygiene 98: 1281-1295. https://doi.org/10.4269/ajtmh.16-0922 
Rood, E.J., Goris, M.G., Pijnacker, R., Bakker, M.I. \& Hartskeerl, R.A. (2017). Environmental risk of leptospirosis infections in the Netherlands: Spatial modelling of environmental risk factors of leptospirosis in the Netherlands. PloS ONE 12: 1-11. https://doi.org/10.1371/journal.pone.0186987

Suut, L., Mazlan, M.N., Arif, M.T., Yusoff, H., Abdul-Rahim, N.A., Safii, R. \& Suhaili, M.R. (2016). Serological prevalence of leptospirosis among rural communities in the Rejang basin, Sarawak, Malaysia. Asia Pacific Journal of Public Health 28: 450-457. https://doi.org/10.1177/1010539516648003

Thayaparan, S., Robertson, I.D., Fairuz, A., Suut, L., Gunasekera, U.C. \& Abdullah, M.T. (2015). Seroepidemiological study of leptospirosis among the communities living in periurban areas of Sarawak, Malaysia. The Medical Journal of Malaysia 70: 288-294.

Togami, E., Kama, M., Goarant, C., Craig, S.B., Lau, C., Ritter, J.M. \& Nilles, E.J. (2018). A large leptospirosis outbreak following successive severe floods in Fiji, 2012. The American Journal of Tropical Medicine and Hygiene 99: 849851. https://doi.org/10.4269/ajtmh.18-0335

Vega-Corredor, M.C. \& Opadeyi, J. (2014). Hydrology and public health: linking human leptospirosis and local hydrological dynamics in Trinidad, West Indies. Earth Perspectives 1: 3-17. https://doi.org/10.1186/2194-6434-1-3
Victoriano, A.F., Smythe, L.D., Gloriani-Barzaga, N., Cavinta, L.L., Kasai, T., Limpakarnjanarat, K., Ong, B.L., Gongal, G., Hall, J. \& Coulombe, C.A. (2009). Leptospirosis in the Asia Pacific region. BioMed Central Infectious Diseases 9: 147155. https://doi.org/10.1186/1471-2334-9-147

Wang, C., Zhong, S., Zhang, F. \& Huang, Q. (2016). Precipitation interpolation by multivariate Bayesian maximum entropy based on meteorological data in Yun Gui-Guang region, mainland China. IOP Conference Series: Earth and Environmental Science. $6^{\text {th }}$ Digital Earth Submit. Beijing, China.

Weisent, J., Rohrbach, B. \& Dunn, J.R. (2012). Socioeconomic determinants of geographic disparities in campylobacteriosis risk: a comparison of global and local modelling approaches. International Journal of Health Geographics. 11: 45-60. https://doi.org/10.1186/1476-072X11-45

Widiastuti, D., Puspitaningsih, D. \& Wijayanti, S.M. (2019). Leptospirosis Outbreak during Rice Harvesting Season in Kebumen, Central Java Indonesia (The First Case Report in Kebumen). Indian Journal of Public Health Research \& Development 10: 654-658. https://doi.org/10.5958/09765506.2019.00576.X 